\title{
Qualquer e o Conceito de Livre-escolha*
}

\author{
(Qualquer and the Concept of Free-choice)
}

\section{Roberta PIREs De OliveIra \\ (UFSC/CNPq)}

\begin{abstract}
The paper develops the idea that 'qualquer'-phrases in Brazilian Portuguese (PB) are indefinites (Heim 1982), a bypothesis introduced by Peres (pc). It is shown that there is just one item 'qualquer', and that the differences between the two syntactic configurations in which it appears - 'um $N$ qualquer' and 'qualquer N' -, are due to the presence of the indefinite 'um'. The comparison between 'um' and 'qualquer' phrases highlights the semantic contribution of the later: it conveys free-choiceness. These facts strongly support the thesis that free choiceness is a feature independent of quantificational force. Free choiceness is, then, explained as a presupposition triggered by 'qualquer'. A formal characterization of this presupposition is presented. It relies upon a decomposition of 'qualquer' in 'qual', a D-linked wh-word, and 'quer', a modal verb. Indifference and ignorance are explained via the assessment of different modal bases. It is shown that the hypothesis also explains other uses of 'qualquer'. The theoretical approach is in consonance with formal analysis of natural language.
\end{abstract}

KEY-WORDS: formal semantics; presupposition; free-choiceness; indefinites.

Resumo: Este artigo desenvolve a hipótese de Peres (cp) de que sintagmas 'qualquer' não são quantificados, mas indefinidos (Heim 1982). Argumenta-se que bá um item 'qualquer' e que as diferenças entre as estruturas 'qualquer N' e 'um N qualquer' devem-se à presença do artigo indefinido 'um'. Comparado ao sintagma-'um', sintagmas-'qualquer' expressam "livre-escolba" que, na análise proposta, é uma pressuposição de alternativas possiveis. Formalmente, ela se deve à presença de 'qual', que necessita,

\footnotetext{
* Agradeço ao apoio financeiro da CAPES que permitiu, através de uma bolsa de pós-doutoramento, minha estadia no MIT como professora visitante. Agradeço a profa. Irene Heim as inúmeras discussões sobre o qualquer. Ao prof. João Peres as nossas conversas sobre quantificadores e, em especial, sua hipótese de que o qualquer é um indefinido. Agradeço ao prof. Kay von Fintel as discussões sobre a pressuposição de alternativas. Os erros são evidentemente todos de minha própria autoria.
}

D.E.L.T.A., 21:2, 2005 (251-277) 
para ser feliz, que um conjunto de alternativas já esteja no fundo compartilhado, e 'quer', que indica contexto modal. Ignorância e indiferença, característicos da livreescolha, são apreendidos através de diferentes bases modais. Explora-se, na conclusão, algumas conseqüências desta abordagem. O quadro teórico se enquadra na reflexão contemporânea da semântica formal das linguas naturais.

PALAVRAS-CHAVEs: semântica formal; pressuposição; livre-escolha; indefinidos.

\section{Introdução}

Uma estratégia metodológica que tem se mostrado eficiente para refletirmos sobre fenômenos das línguas naturais é imaginar como seria a teoria se os fatos a serem explicados não viessem do inglês; evitaríamos, dessa maneira, uma prática que pode se mostrar perversa: olhar para o português (ou outra língua natural qualquer) a partir da perspectiva teórica criada para explicar o inglês. Nesse artigo, seguindo essa metodologia introduzida em Matthewson (2001), vamos endereçar a noção teórica de livre-escolha (free choiceness) a partir da análise de qualquer no Português Brasileiro (PB). Essa noção, introduzida, segundo Haspelmath (1997), por Vendler (1967) no famoso texto sobre o any, embora muito utilizada, não foi ainda formalmente descrita de maneira satisfatória e, provavelmente devido ao fato de que ela foi estudada tendo como ponto de análise o item lexical any do inglês, se misturou nefastamente ao problema da força quantificacional. Como mostraremos manter esses dois conceitos separados é não apenas teoricamente mais satisfatório, porque permite refletirmos isoladamente sobre cada um, mas empiricamente mais adequado.

Há dois fatos marcantes sobre o qualquer no PB que são os condutores desse estudo:

1. O fato de que ele ocorre em duas formas sintagmáticas, qualquer $N$ e um $N$ qualquer, que, em certos contextos, são sinônimas, mas cuja substituição nem sempre é possível, como atesta o fato de que apenas a sentença em (2) é ambígua entre uma leitura genérica caracterizadora e uma leitura genérica habitual, em que se está falando sobre um (cardinal) aluno cuja identidade é desconhecida ou irrelevante; interpretação que não está disponível para a sentença em (1):

(1) Qualquer aluno joga futebol.

(2) Um aluno qualquer joga futebol. 
A sentença em (2) está muitas vezes associada a uma atitude depreciativa por parte do falante; iremos, no entanto, considerar, sem desenvolver o tópico, que esse "significado" é, na verdade, uma implicatura conversacional $^{1}$;

2. O fato de que sintagmas nominais com qualquer mostram variabilidade de interpretação, podendo, descritivamente, ter leitura existencial ou universal. As sentenças em (1) e (2) apresentam leitura genérica, ao passo que as sentenças em (3) e (4), sinônimas, têm leitura existencial:

(3) Deu qualquer problema com o computador.

(4) Deu um problema qualquer com o computador.

A literatura sobre o any indica uma terceira característica dos itens de livre escolha que, segundo Móia (2002), também se aplica aos sintagmasqualquer: eles são contextualmente limitados, isto é, têm uma distribuição restrita. Nada falaremos sobre este último aspecto.

Do que pudemos identificar, são poucas as análises sobre os sintagmas-qualquer. ${ }^{2}$ Guimarães (1995) aplica a idéia de livre-escolha de Vendler (1967) para o qualquer no português, mas não discute nenhum dos fatos descritos acima. Gomes (em preparação) trata os dois sintag mas qualquer $N$ e um $N$ qualquer como distintos, argumentando que no primeiro caso temos um quantificador e no segundo um adjetivo, sinônimo de não importa qual. A autora não trata, no entanto, do problema da variabilidade de interpretação e não apresentou até o momento uma proposta de descrição. Móia (2002), desenvolvendo hipóteses levantadas em Peres (1987), descreve os dois sintagmas como variantes semânticos e apresenta com muita clareza a variabilidade de interpretação. Em sua análise a variabilidade, que, para este autor, se abre em três acepções básicas - a universal, a existencial e a cardinal - é explicada como um caso de homonímia; não há, no entanto, uma proposta de explicação para a homonímia. Assim, até onde pudemos investigar, não há uma proposta de descrição da semântica de qualquer.

1 Há, também, o que Haspelmath (1997) chama de série dos indefinidos: qualquer um, qualquer coisa, qualquer lugar,..., que mostram um comportamento particular, mas não iremos desenvolver esse tópico neste artigo.

2 Já sobre o any há uma vasta literatura. Entre outros: Vendler (1967), Lee \& Horn (1995), Horn (2002), Dayal (1998), von Fintel (2000), Saebo (2001), Giannakidou (2001), entre outros. 
Este artigo entende que há apenas um item qualquer, disparador de uma pressuposição responsável pela interpretação de livre-escolha, e explica a variabilidade de interpretação desenvolvendo a idéia, apresentada pela primeira vez por Peres (conversa pessoal), de que este item é um indefinido no sentido de Heim (1982). Este é o tema da próxima seção. A despeito da similaridade de usos dos dois sintagmas-qualquer (veja sentenças acima), eles apresentam, em contextos particulares, comportamentos distintos, como já apontado com relação à sentença em (2). Mostramos as diferenças mais relevantes na seção 2, para então, na seção 3, explicá-las pela presença do indefinido um. Estes dois fatos juntos constituem um forte argumento para tratar livre-escolha e força quantificacional como propriedades independentes; compartilhando neste aspecto a proposta de Kratzer \& Shimoyana (2002). A seção seguinte busca determinar, no nível intuitivo, a contribuição semântica de qualquer comparando-o à construção indefinida um N. Apenas qualquer veicula livre-escolha, caracterizada através das noções de indiferença e ignorância (as sentenças em (3) e (4) expressam ignorância por parte do falante, enquanto que em (1) e (2) veicula-se indiferença). Na seção 5, retomamos alguns casos problemáticos que poderiam ser argumentos para reatar livre-escolha e força quantificacional, mostrando que é possível encaminhar uma explicação para eles dentro do quadro teórico que estamos construindo. Na seção 6, apresentamos a hipótese explicativa central deste artigo que entende que qualquer veicula uma pressuposição de alternativas possíveis. As noções de indiferença e ignorância são apreendidas através da idéia de que diferentes bases modais estão presentes na interpretação de sentenças qualquer. Apresentamos, nessa seção, uma descrição formal dessa pressuposição. Como conclusão discutimos algumas conseqüências que essa análise têm para a descrição de sintagmas nominais no PB.

\section{Qualquer: um indefinido.}

Heim (1982) (mas veja também Chierchia 1995) define indefinidos através da presença de duas características: indefinidos apresentam variabilidade de interpretação e podem "ligar" variáveis que estão além do seu "escopo" (as aspas marcam que essa descrição não é precisa; afinal não se trata de uma questão de escopo). Já mostramos que qualquer ora é interpretado universal ora existencialmente, isto é, ele apresenta variabilidade quanficacional. 
A segunda propriedade pode ser exemplificada pela sentença abaixo, a famosa sentença do burro:

(5) Todo fazendeiro que tem um burro $_{i}$ bate nele $e_{i}$.

Em (5), o pronome ele é correferente de um burro. Essa "ligação", no entanto, não pode ser explicada via escopo ou c-comando porque não há tal relação entre eles. Note que o mesmo fenômeno se evidencia com os sintagmas com qualquer (sentenças (6) e (7)), em contraste com a sentença em (8) em que há um quantificador universal ${ }^{3}$ e a ligação entre os sintagmas nominais não é possível:

(6) Todo fazendeiro que tem um burro qualquer bate nele.

(7) ? Todo fazendeiro que tem qualquer burro bate nele.

(8) * Todo fazendeiro que tem todo burro bate nele.

Para explicar esses fatos, Heim (1982) levanta a hipótese de que indefinidos não são sintagmas quantificados, mas apenas introduzem variáveis que estão presas por algum quantificador sentencial ou discursivo que prende não-selecionalmente. ${ }^{4}$ Se são esses os critérios para indefinidos, então qualquer não é um quantificador, mas um indefinido, isto é, ele marca a presença de uma variável ${ }^{5}$.

A autora distingue ainda a indefinitude do conceito de familiaridade (ou definitude). Algo é familiar se aciona informações já presentes no contexto discursivo, no fundo conversacional compartilhado. O pronome ele na sentença em (6) é familiar porque sua interpretação depende de haver um referente discursivo já presente no fundo conversacional. Já o sintagma um burro, na mesma sentença, é não-familiar, isto é, ele introduz um referente discursivo novo. Indefinidos podem, portanto, ser familiar ou nãofamiliar. A distinção entre familiar e novo será retomada mais adiante.

\footnotetext{
3 Para argumentos sustentando a hipótese de que todo é um quantificador universal e não um indefinido ver Pires de Oliveira (2003) e Negrão (2002) para uma posição diferente.

4 Para uma apresentação detalhada do modelo ver a própria Heim (1982), Chierchia (1995).

5 Lee \& Horn (1995) levantam essa mesma hipótese para o any: ele seria um indefinido que carrega uma implicatura escalar. Giannakidou (2001) também mostra que o item lexical que expressa livre escolha em grego é um indefinido. Nenhuma dessas propostas é adequada para explicar o qualquer. Não vamos, no entanto, mostrar esse ponto neste artigo.
} 
Se sintagmas-qualquer são indefinidos, então já temos uma razão para dissociar quantificação de livre-escolha, que, como veremos, é a contribuição semântica dada por esses sintagmas.

\section{Diferenças entre um $\mathbf{N}$ qualquer e qualquer $\mathbf{N}$}

A despeito das semelhanças entres as sentenças (1) e (2), e (3) e (4), as estruturas qualquer $N$ e um $N$ qualquer não mostram o mesmo comportamento em todos os contextos discursivos. Vamos identificar essas diferenças, descrevendo suscintamente as principais posições sentenciais.

\subsection{Posição de sujeito}

Há duas diferenças marcantes com relação à posição de sujeito (entendido como argumento externo do predicado): quando em sentenças genéricas $^{6}$ apenas um $N$ qualquer mostra variabilidade de interpretação, podendo ter leitura caracterizadora ou habitual; qualquer $N$ só tem leitura caracterizadora. Já mostramos esse caso quando comparamos as sentenças em (1) e em (2). A sentença em (2) pode tanto ser interpretada como uma sentença genérica caracterizadora, expressando que não importa qual seja o aluno, ele gosta de futebol, quanto uma sentença habitual em que se afirma de um aluno, cuja identidade não é conhecida, que ele tem o hábito de jogar futebol. Essa segunda interpretação, em que o sintagma nominal refere a um indivíduo (cardinal) não está disponível para a sentença em (1).

Em sentenças episódicas, um $N$ qualquer é, do ponto de vista descritivo, sempre interpretado existencialmente (mais especificamente como um cardinal), ao passo que qualquer $N$ é, se aceito, interpretado como expressando um "universal". Se observarmos nossas intuições sobre as sentenças em (9), notamos que em (9a) só temos interpretação existencial-cardinal tanto do sintagma nominal, um aluno qualquer, que denota um indivíduo, quanto do evento. Essa interpretação explica-se, parcialmente, pelo fato de que a sentença está sob escopo de um operador existencial, provavelmente fornecido pela morfologia verbal; retornaremos ao problema da car-

6 Estamos adotando o conceito de genericidade tal qual apresentado em Krifka et al. (1995). 
dinalidade mais adiante. Mantendo o mesmo padrão de (1), (9b), se acei$\mathrm{ta}^{7}$ é interpretada como se referindo a cada uma das alternativas de um grupo de alunos, contextualmente determinado: não importa qual aluno (de um grupo particular de alunos) seja escolhido, ele resolveu o problema; isto é, a única interpretação possível é "universal”, embora a sentença esteja no pretérito:

(9) a. Um aluno qualquer resolveu o problema.

b. ? Qualquer aluno resolveu o problema.

A sentença em (10a) confirma a "dificuldade", talvez impossibilidade, de interpretarmos o sintagma-qualquer como denotando um indivíduo, em comparação com (10b), em que a interpretação cardinal, a única disponível, é natural:

(10) a. \# Qualquer médico operou este paciente aqui. ${ }^{8}$

b. Um médico qualquer operou este paciente aqui.

Chegamos, pois, ao seguinte quadro com relação à posição de sujeito:

\begin{tabular}{|l|l|l|} 
& Qualquer N & Um N qualquer \\
\cline { 1 - 1 } Genérico & $\forall$ & $\forall$ ou $\exists \mathrm{c}$ \\
\cline { 1 - 1 } Episódico & $\#(\forall)$ & $\exists \mathrm{c}$ \\
\hline
\end{tabular}

$\exists c=$ Existencial cardinal

\footnotetext{
Fizemos uma pequena pesquisa sobre a aceitabilidade e interpretação de sentenças com qualquer com 23 falantes do PB. A sentença em (9b) foi aceita por alguns. No entanto, tanto Peres (1985) quanto Móia (2002) afirmam que qualquer N não pode ocorrer com perfectivos. Giannakidou (2001) afirma o mesmo sobre o item de livre-escolha em grego. Finalmente, na pesquisa em corpus escrito que realizamos informalmente não encontramos um único exemplo de qualquer com perfectivo, a não ser quando co-ocorrendo com a negação, mas não vamos tratar aqui da negação. 8 O símbolo \# é utilizado para indicar "estranhamento", não necessariamente agramaticalidade. Não iremos, no entanto, discutir essa questão neste texto. Nenhum dos 23 entrevistados atribuiu qualquer interpretação a sentença (10.a).
} 


\subsection{Posição de objeto}

$\mathrm{Na}$ posição de objeto (argumento interno), um $\mathrm{N}$ qualquer tem sempre leitura existencial (cardinal), mesmo quando em sentenças genéricas, como é o caso de (13):

(11) Chegou uma carta qualquer.

(12) Maria comprou um vestido qualquer.

(13) Sempre que João almoça, ele come um doce qualquer de sobremesa.

A situação com qualquer $N$ é muito mais difícil de descrever. Em geral, "out of the blue", sentenças em que qualquer $N$ aparece na posição de objeto não soam bem:

(14) \# Chegou qualquer carta.

(15) \# Ela comprou qualquer vestido.

Mas: 1. nem sempre é este o caso, compare os exemplos em (14) e (15), com (16) e (17) abaixo:

(16) Hoje, o João colocou qualquer roupa.

(17) Vendo qualquer CD.

Note que (16) é existencial, mas não cardinal, ao passo que (17) é universal.

2. a sentença melhora se modificamos o objeto com uma sentença restritiva (este é o fenômeno que Dayal (1998), seguindo LeGrand, denomina "subtrigging" e que também ocorre com any), veja o exemplo na sentença abaixo:

(18) O João conversou com qualquer mulher que ele encontrou.

3. o sintagma qualquer $N$ pode ter interpretação universal, exemplo em (19), ou ser ambíguo, como em (20): ela comprou um jornal não importa qual, ou ela comprou todos os jornais da banca (não importando qual era):

(19) Deus perdoa qualquer pecado.

(20) A Maria comprou qualquer jornal que tinha na banca. 
Assim, na posição de objeto há, de maneira mais acentuada, discrepâncias no comportamento dos sintagmas-qualquer, explicitadas no quadro abaixo.

\begin{tabular}{|ll|l|}
\hline Genérico & $\begin{array}{l}\text { Qualquer } \mathrm{N} \\
\text { ou }\end{array}$ & $\begin{array}{l}\text { Um N qualquer } \\
\exists \mathrm{c}\end{array}$ \\
\hline Episódico & $\#$ ou $\forall$ ou $\exists$ & $\exists \mathrm{c}$ \\
\hline
\end{tabular}

\section{Explicando as diferenças}

Parece natural comparar sintagmas-qualquer com sintagma-um porque, como já mostramos na seção 2 , eles apresentam comportamento semelhante: ambos são indefinidos, diferentemente de todo $N$ que é um quantificador (mais adiante iremos também comparar os sintag mas-qualquer com todo); isto é, eles apresentam variabilidade de interpretação e "prendem" variáveis além de seu "escopo". Essa comparação interessa particularmente porque ela permite, por um lado, explicar as diferenças entre qualquer $N$ e um $N$ qualquer, o que faremos nesta seção, e, por outro, esclarecer a contribuição semântica de qualquer, o que faremos na próxima seção.

Do ponto de vista quantificacional, um $N$ qualquer apresenta exatamente o mesmo comportamento de $u m N$, o que leva à hipótese de que a diferença entre os sintagmas-qualquer deve-se à presença do artigo indefinido $u m$. Se este for o caso, temos mais um argumento para dissociar livreescolha de força quantificacional.

\subsection{A presença de um}

O sintagma um $N$ é ambíguo, quando em posição de sujeito de sentenças genéricas, podendo receber tanto uma leitura genérica caracterizadora, quanto uma leitura cardinal genérica-habitual, como atesta a sentença abaixo:

(21) Um brasileiro joga de futebol. 
Se sujeito de sentença episódica, sua interpretação é existencialcardinal:

(22) Um aluno resolveu o problema.

Na posição de objeto, a leitura também é sempre existencial-cardinal, mesmo em sentenças genéricas, como (24):

(23) A Maria comprou um vestido.

(24) A Maria come um doce depois do almoço.

O quadro abaixo mostra que o comportamento de um $N$ qualquer e um $N$ nas duas posições é absolutamente idêntico:

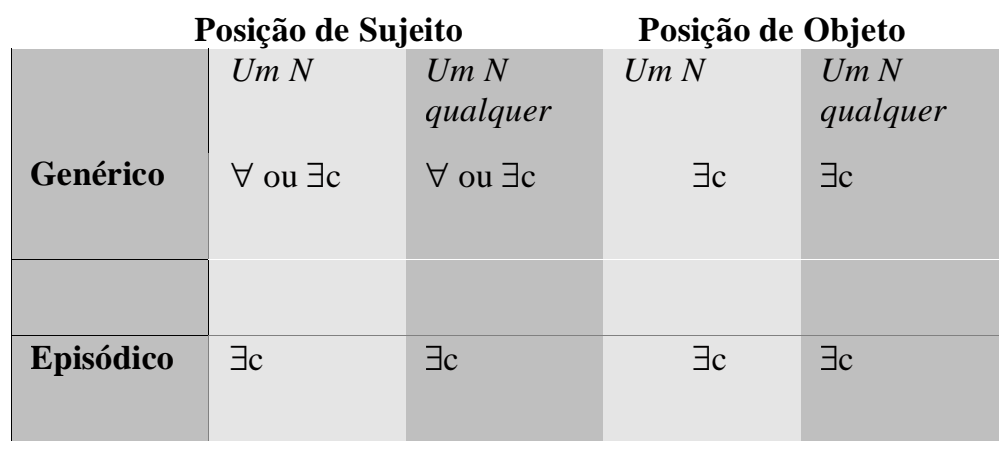

Müller (2002) argumenta que o indefinido um $N$ é existencialmente interpretado na posição de objeto porque ele está sob o escopo de um operador existencial fornecido ou pela morfologia verbal, como no exemplo em (23), ou porque ele está no escopo nuclear de uma sentença genérica que é fechada por um operador existencial, sentença em (24). A morfologia verbal também explica, na análise da autora, a interpretação existencial desse sintagma quando na posição de sujeito de sentenças episódicas, como no exemplo em (22). A autora argumenta ainda que a morfologia de singular de sintagmas nominais no PB tem valor semântico: $u m$ refere aos átomos de uma estrutura semi-reticular fornecida pelo nome comum, o que permite que ele tenha uma interpretação cardinal (de numeral), quando interpretado existencial. Assim, a sentença em (21), que está sob o escopo de um operador genérico, fornecido pela morfologia do presente, é 
ambígua entre a interpretação genérica do $\mathrm{SN}$ e a interpretação cardinal. No primeiro caso, temos uma sentença caracterizadora, no segundo, uma sentença habitual. Essas explicações se aplicam diretamente ao sintagma um $N$ qualquer. Em outros termos, a variabilidade de interpretação deste sintagma se explica pelo comportamento do indefinido $\mathrm{um}$.

A hipótese de que a interpretação quantitativa se deve à presença de $u m$ no sintagma um $N$ qualquer prediz que as sentenças abaixo têm diferentes interpretações, porque apenas em (25) podemos ter a leitura cardinal, isto é, houve apenas um policial que a Maria namorou. Essa possibilidade está excluída como interpretação da sentença em (26), que, se aceita, interpreta-se como sendo o caso que Maria tenha encontrado mais de um policial na vida (mas não exatamente um), o que condiz com a nossa intuição:

(25) A Maria namorou um policial qualquer.

(26) A Maria namorou qualquer policial (que ela encontrou na vida).

\section{Um Ne sintagmas-qualquer: pressuposição}

Dado que um $N$ qualquer e $u m N$ mostram, do ponto de vista quantificacional, comportamento absolutamente idêntico, poderíamos supor que não há diferença semântica entre eles. Não é esse, no entanto, o caso. Apenas os sintagmas-qualquer apresentam o efeito de livre-escolha. Se pudermos demonstrar isto, então confirmamos nossa hipótese de que livre-escolha e força quanticacional são propriedades (traços, na proposta de Kratzer \& Shimoyana (2002)) independentes.

A literatura, desde Vendler (1967), associa a idéia de livre-escolha a algum tipo de "indiferença" com relação ao referente; o que é captado por paráfrases como "não importa qual". Indiferença com respeito tanto ao fato de que a identidade do referente não é conhecida, quanto ao fato de que ela não interfere nas condições de verdade da sentença (tanto faz saber qual é o referente) ${ }^{9}$. Essa parece ser efetivamente a contribuição semântica de qualquer e pode ser captada através de um exemplo desenhado por Kratzer e Shimoyama (2002) como uma maneira de diferenciar o uso de irgendein

9 Ver em especial von Fintel (2000). 
do uso de ein ${ }^{10}$ um problema paralelo à diferença entre sintagmas-qualquer e o sintagma-um. Imagine uma situação em que a sentença em (27) é usada como resposta para a pergunta "alguém telefonou?"

(27) Uma pessoa qualquer ligou.

Ao usar qualquer o falante veicula a informação de que ele não sabe quem telefonou ou que ele não se importa com a identidade do referente. É por isso que a seqüência discursiva em (28) é estranha:

(28) Uma pessoa qualquer ligou.

\# Quem era?

Veja o contraste com a seqüência em (29), absolutamente natural:

(29) Uma pessoa ligou.

Quem era?

A pergunta "quem era?" não cabe no contexto de qualquer porque há uma incompatibilidade entre o que o falante veiculou ao usar qualquer, a identidade do referente é ou desconhecida ou irrelevante, e o que a pergunta denota. Como o sintagma-um não veicula nada sobre como o falante se posiciona quanto ao referente, a pergunta faz sentido. Apenas sintagmasqualquer indicam que a identidade do referente não se coloca, quer porque ela não é conhecida, quer porque ela não é relevante. É nesse sentido que qualquer carrega uma pressuposição de alternativas possíveis, discutida na próxima seção.

O cenário discursivo a seguir mostra o mesmo contraste. Suponha uma conversa que inicia com a seguinte pergunta:

(30) - Com quem a Maria casou?

(31a) não é uma resposta adequada à pergunta em (30), enquanto que (31b) é:

10 Irgendein deve ser traduzido para o PB por algum que, ao que tudo indica, também carrega o traço de livre escolha, embora ele seja um existencial (mais um argumento para dissociarmos força quantificacional de livre-escolha). Não vamos, no entanto, ter espaço para desenvolver este tópico. 
(31) a. \# Com qualquer médico, o Carlos. ${ }^{11}$

b. Com um médico, o Carlos

A razão é a mesma: não é consistente com o uso de qualquer que o falante conheça a identidade do referente ou que ela seja relevante para a avaliação da sentença.

Considere agora uma situação em que o domínio de médicos é constituído por quatro indivíduos: Pedro, Carlos, João e André. As sentenças em (32) e (33) podem ser usadas com felicidade nesse contexto:

(32) A Maria quer casar com um médico qualquer.

(33) A Maria quer casar com um médico.

Se, no entanto, a situação é alterada minimamente, a sentença em (32) não é mais adequada. Suponha que embora o domínio tenha quatro indivíduos, apenas com dois deles, Carlos e Pedro, a Maria se casaria. Nesse contexto, a sentença em (32) não pode mais ser usada com felicidade, porque não é mais verdade que a Maria se casaria com qualquer uma, não importa qual, das alternativas de médico. A sentença em (33) continua sendo uma boa possibilidade nesse novo cenário precisamente porque ela não pressupõe que os referentes estejam todos disponíveis. Veja que nesse caso estamos diante de indiferença, mas o mesmo raciocínio se aplica para ignorância, como mostrado no próximo exemplo.

Suponha que dez bicicletas estejam à vista e disponíveis para a venda, mas que o falante tem certeza de que oito dessas bicicletas a Maria não compraria, embora ele não saiba qual das duas bicicletas restantes ela comprou, a bicicleta $a$ ou a bicicleta $b$. Nessa situação, a sentença abaixo é infeliz ${ }^{12}$ :

(34) A Maria comprou uma bicicleta qualquer.

No entanto, se todas as bicicletas podem, por hipótese, ser alternativas, então a sentença é feliz. Note que a sentença com o indefinido um é boa nas duas situaçõos:

11 Se a informação de que o falante sabe qual é o referente discursivo pertencer ao fundo conversacional compartilhado, então o uso de uma sentença como (31a) vai gerar uma implicatura conversacional. Não vamos, no entanto, tratar deste ponto aqui.

12 Agradeço o exemplo a von Fintel (cp) 
(35) A Maria comprou uma bicicleta.

Se tanto um $N$ quanto qualquer $N$ são marcadores da presença de variável, então, uma maneira de explicar a diferença entre eles é desenvolver a hipótese de que qualquer carrega algum tipo de pressuposição que permite inferirmos que a identidade do referente não é relevante para as condições de verdade da sentença. Se esse for o caso, então para que uma sentençaqualquer seja feliz é preciso que haja já disponível um domínio de alternativas possíveis. $U m N$ não carrega tal pressuposição. Em outros termos, qualquer é familiar, ao passo que um é não-familiar.

\section{Explicando o comportamento quantificacional de qualquer $\mathbf{N}$}

Antes de endereçarmos a questão da pressuposição é preciso garantir que nossa hipótese básica esteja correta: se de fato força quantificacional e livre-escolha são independentes, então a quantificação sentencial deve ser suficiente para explicar a variabilidade de interpretação de qualquer $N$ e um $N$ qualquer. Já mostramos que a variabilidade deste último se explica pela contribuição de um. Há, no entanto, pelo menos dois casos problemáticos com o primeiro sintagma que precisam ser explicados para garantirmos que força quantificacional e livre-escolha são de fato independentes. Já dissemos que nem todos aceitam a sentença em (9b), repetida abaixo. No entanto, se aceita, ela é interpretada como sendo sobre um conjunto de alunos contextualmente saliente: cada um dos alunos resolveu o problema.

(36) Qualquer aluno resolveu o problema.

Note que a quantificação sentencial é existencial, dada pela morfologia do pretérito. Aparentemente a melhor paráfrase para (36) é: há um grupo de alunos, contextualmente compartilhado, e cada um deles resolveu o problema. Embora a quantificação sentencial seja existencial, a base modal parece ser contrafactual, pois o falante não pretende veicular que ele não sabe quem é o referente, mas antes que não importa qual referente do conjunto seja escolhido, a asserção será verdadeira. Se assim for teremos algo como: para todo elemento do conjunto de alunos (contextualmente dado), em todos os mundos que se seguem dos mundos em que ele é um aluno em questão ele resolveu o problema. O que permiti essa interpreta- 
ção é a hipótese de que aluno expressa um grupo de alunos, e essa inferência parece ser contextual. No caso do sintag ma um $N$ qualquer essa alternativa é vedada pela presença de um.

Um outro caso problemático diz respeito ao fato de a sentença em (37) pode ter uma interpretação genérica: para toda coisa que tinha na geladeira, é verdade que a Maria comeu ela. Essa interpretação não é possível para a sentença em (38) em que não ocorre a modificação relativa. Aparentemente a sentença em (37) poderia ainda ter uma leitura existencial. As leituras existenciais são facilmente explicáveis pela presença de uma morfologia de pretérito. O mistério é o fato de que o acréscimo de uma sentença relativa possa fazer aparecer uma interpretação genérica. Este é em si um fenômeno pouco compreendido na literatura e é conhecido, a partir do trabalho de LeGrand, como "subtrigging" (apud Dayal 1998). Este, no entanto, é um tópico em si cuja explicação não depende da presença de qualquer:

(37) A Maria comeu qualquer coisa que tinha na geladeira.

(38) A Maria comeu qualquer coisa estragada.

\section{Pressuposição de alternativas possíveis}

Vimos, na seção anterior, que as diferenças semânticas entre os sintagmas-qualquer e o sintag ma-um podem ser explicadas através da hipótese de que apenas os primeiros indicam "livre-escolha". Este, no entanto, não é um conceito claro na literatura. A idéia de que o falante pode escolher livremente se aplica com muita propriedade a sentenças genéricas, como as sentenças em (1) e (2), mas não condiz com os usos em que se expressa ignorância, como é o caso das sentenças (3) e (4), a menos que se entenda que se pode escolher livremente a alternativa porque não se sabe qual é a alternativa correta, mas, nesse caso, estamos lidando com uma outra noção de livre-escolha. Uma maneira de uniformizar é entender que livreescolha significa que se introduz uma pressuposição de alternativas possíveis, todas elas com valor idêntico, e atribuir ignorância ou indiferença a algum outro elemento. $\mathrm{Na}$ hipótese que vamos desenvolver, indiferença e ignorância são alcançados através de diferentes bases modais. Nessa seção vamos esmiuçar essa hipótese, buscando formalizá-la. 
A questão da pressuposição é espilhosa e constitui um tema em si mesma. Parece, no entanto, ser consenso que algo é pressuposto se e somente se ele é acarretado pelo fundo comum (Stalnaker 1974, Karttunen 1974, Heim 1990). É precisamente essa a razão que explica o fato, já assentado na literatura, de que a pressuposição se mantém a despeito de operarmos com a sentença que a contém. Manipulamos o conteúdo assertado, mas mantemos aquilo que é informação disponível no fundo conversacional compartilhado. Assim, se a existência de alternativas possíveis é uma pressuposição, ela deve se projetar e é precisamente isso o que ocorre. Considere a sentença complexa abaixo:

(39) A Maria sabe que deu qualquer problema com o computador.

É fácil notar que a existência de um conjunto de problemas passíveis de terem afetado o computador se mantém, assim como o fato de que não se sabe qual é o problema - no caso dessa sentença parece ser possível interpretar que a ignorância é ou do sujeito da sentença ou do falante ou de ambos, voltaremos ao tópico mais adiante. Temos, pois, base para sustentar nossa hipótese. Ela também depende, como já mostramos, de mantermos separadas as questões da quantificação sentencial e da livre-escolha que parece se sustentar empiricamente. Não vamos endereçar o tópico da quantificação neste artigo, mas adotar o que é consenso na literatura.

Por exemplo, na sentença em (40), o sintagma-qualquer está sob o escopo de um operador existencial porque ele ocorre no escopo nuclear de uma sentença genérica; já este sintagma, na sentença em (41), tem que ser interpretado "universalmente", pois ele está na matriz de uma sentença genérica e, portanto, sob o escopo do operador genérico. Não há nada de novo nestas descrições. Apresentamos em (a) uma primeira aproximação da forma lógica dessas sentenças, porque elas serão utilizadas mais adiante na descrição do funcionamento da pressuposição:

(40) A Maria coloca qualquer roupa quando está em casa.

a. Gen [s, x; y] [Situação-de-estar-em-casa s, Maria x, está em (x, s); Roupa y, Veste $(\mathrm{x}, \mathrm{y})]$

(41) Qualquer adolescente chora.

a. Gen [x; ] [ Adolescente x; Chora x] 
As formas em (a) não podem ser a descrição final da semântica das sentenças em (40) e (41), respectivamente, por várias razões. Considere, primeiramente, a sentença em (41). Se a forma lógica em (a) exaurisse o que ela veicula, ela seria absolutamente sinônima da sentença em (42):

(42) Um adolescente chora.

Como já argumentamos, há uma diferença entre essas sentenças: apenas a sentença em (41) veicula a idéia de que o "avaliador" da sentença pode escolher livremente a alternativa que ele quiser. É precisamente essa idéia que vamos capturar na pressuposição de alternativas. Além disso, a literatura sobre o any, a partir do trabalho de Kadmon \& Landman (1993), tem apontado como uma característica da livre-escolha o fato de que há uma ampliação do domínio de indivíduos. O argumento que eles usam para sustentar essa hipótese está reproduzido no diálogo abaixo:

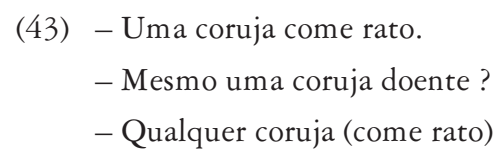

Supostamente o genérico com o indefinido um pode se aplicar a domínios mais restritos, enquanto que o uso de qualquer produz, na interpretação proposta neste artigo, uma ampliação de um domínio já previamente dado como parte do fundo conversacional. No caso do exemplo em (43), o conjunto de corujas é introduzido na primeira fala, os limites desse conjunto estão em questão na pergunta em seguida, e finalmente, qualquer recupera o conjunto em seu limite máximo, isto é, incluindo as corujas doentes.

Compare, agora, a sentença em (40) com a sentença com o indefinido um abaixo:

(44) A Maria veste uma roupa quando está em casa

A sentença em (44), diferentemente de (40), soa estranha. Ela implica, pragmaticamente, que quando não está em casa a Maria não veste roupa alguma. Esta implicatura pode se dever ao fato de que se todos sabemos que estamos sempre vestidos, então proferir (44), em que se veicula uma interpretação cardinal de roupa, não é informativo. Logo, se o falante o fez é porque ele quis dizer outra coisa e temos a implicatura. O ponto é que a 
sentença em (40) não levanta qualquer implicatura, mesmo que tivéssemos ao invés de qualquer roupa, uma roupa qualquer; a presença de uma, que impõe uma leitura cardinal, não impede que a sentença continue a ser informativa e, portanto, não veicula a mesma implicatura que a sentença em (44). Se, em termos de conteúdo, um proferimento com qualquer expressa a mesma proposição que um proferimento com o indefinido um, então a informatividade de (40) deve vir da pressuposição disparada por qualquer. É este o ponto que vamos mostrar na próxima seção.

\subsection{A pressuposição de Alternativas Possiveis}

A pressuposição disparada por qualquer resulta da combinação de dois elementos: qual, cujo uso feliz, como nas interrogativas, depende de haver um conjunto de alternativas de respostas já disponíveis contextualmente (trata-se de um wh D-linked na abordagem de Pesetsky (1987)), e quer, que é um verbo modal, e, portanto, introduz intensionalionalidade. O contexto tem um papel duplo na especificação da pressuposição: ele restringe o conjunto de alternativas àquelas que são relevantes e indica a base modal de interpretação. Segundo a descrição de von Fintel (2000), há duas possibilidades de interpretarmos a livre-escolha, como uma escolha aleatória porque não faz diferença qual é o referente indicado (trata-se da interpretação de indiferença presente na sentença em (41), por exemplo), ou como

um desconhecimento do referente e, portanto, a assunção de que todas as alternativas são candidatas em potencial (este é o caso de ignorância exemplificado na sentença em (39)). No primeiro caso, temos uma base modal (nos moldes propostos por Kratzer 1981) contrafactual, no segundo, a base modal é epistêmica. Na interpretação contrafactual não se coloca o ponto de vista, porque se está fazendo uma generalização, enquanto na epistêmica é possível expressar diferentes perspectivas de ignorância. $\mathrm{Na}$ sentença em (3), por exemplo, trata-se da ignorância do falante, já em (36) a ignorância pode ser tanto do falante quanto do sujeito da sentença, quanto de ambos. Fica a cargo do contexto a determinação da perspectiva de ignorância.

Vejamos como funciona a análise aplicando-a ao exemplo em (3), repetido aqui por conveniência:

(45) Deu qualquer problema no computador. 
Ao proferir (45) o falante implica que desconhece qual é o problema que afeta o computador em questão, e afirma que o computador tem um problema. Grosseiramente, a asserção é:

(46) $\exists x(P x \& D x)$

$\mathrm{P}=$ problema-que-o computador-pode-ter $\mathrm{D}=\mathrm{dar}$

Qualquer dispara a pressuposição de que há um conjunto de problemas passíveis de serem problemas-que-o-computador-tem: vírus, cabo desconectado, má instalação do hardware... E, dado que inferimos que o falante não sabe qual é o problema, a base modal é epistêmica. Afinal se ele soubesse qual é o problema, então, sendo cooperativo, ele não poderia usar qualquer. Temos, pois, os dois ingredientes para a construção da pressuposição: a base modal é epistêmica (se refere ao conhecimento do falante), e há um conjunto de alternativas relevantes. Em linguagem corrente, a pressuposição é:

(46) Por tudo o que o falante sabe, isto é, em todos os mundos que constituem sua base de conhecimento, há um conjunto de problemas passíveis de estarem ocorrendo com o computador, e para cada um dos problemas desse conjunto há um mundo em que ele ocorre com o computador em questão (e não há uma alternativa que torne a proposição verdadeira em todos os mundos da base modal).

Note que a pressuposição afirma que em todos os mundos ocorre um problema no computador, do conjunto de problemas passíveis de ocorrer no computador em questão. Em outros termos, o falante sabe que houve um problema com o computador e sabe que diferentes problemas ocorreram em diferentes mundos; daí se infere que o falante não sabe qual é o problema que ocorreu no mundo atual: o falante sabe que uma das alternativas é a do mundo atual, mas não sabe qual é ela. Em outros termos, ele não sabe escolher qual é a alternativa do mundo atual, embora saiba que ela é uma das alternativas possíveis.

Esquematicamente, suponha que a base modal do falante contém três mundos, $\left\{\mathrm{w}_{1}, \mathrm{w}_{2}, \mathrm{w}_{3}\right\}$ e são três os problemas passíveis de ocorrerem com o computador $\{a, b, c\}$. Eis uma situação possível:

$\begin{array}{lll}\mathrm{w}_{1} & \{\mathrm{a}, \mathrm{b}\} & \mathrm{a} \\ \mathrm{w}_{2} & \{\mathrm{a}, \mathrm{c}\} & \mathrm{c} \\ \mathrm{w}_{3} & \{\mathrm{a}, \mathrm{b}, \mathrm{c}\} & \mathrm{c}\end{array}$


$\mathrm{Em} \mathrm{w}_{1}$, o computador tem o problema a; em $\mathrm{w}_{2}$, o problema c; em $\mathrm{w}_{3}$, o problema c. Precisamos excluir a seguinte situação:

$\begin{array}{lll}\mathrm{w}_{1} & \{\mathrm{a}, \mathrm{b}\} & \mathrm{a} \\ \mathrm{w}_{2} & \{\mathrm{a}, \mathrm{c}\} & \mathrm{a} \\ \mathrm{w}_{3} & \{\mathrm{a}, \mathrm{b}, \mathrm{c}\} & \mathrm{a}\end{array}$

Porque se for essa a situação, então o falante sabe precisamente qual é o problema com o computador. Temos, pois, que garantir que há pelo menos dois mundos em que as alternativas que tornam a asserção verdadeira são distintas. Não basta, portanto, garantir que temos um conjunto com dois elementos distintos; é preciso que haja dois mundos em que o elemento escolhido é distinto. Dito de outra forma, é preciso haver alternativas distintas nos mundos da base modal para que qualquer seja usado com felicidade. Para garantir isso adicionamos uma restrição à base modal: na base modal deve haver pelo menos dois mundos em que o problema é diferente. Já mostramos, na seção anterior, que além de haver alternativas e preciso que todas as alternativas estejam disponíveis; essa parte é garantida pela operação de universalidade.

Em termos formais, a proposta é:

(47) Restrição à base modal:

$\mathrm{F}^{\prime}=\mathrm{F}($ base modal $) \cap \exists \mathrm{w}^{\prime}, \mathrm{w}^{\prime \prime}: \mathrm{P}(\mathrm{x})_{\mathrm{w}^{\prime}} \neq \mathrm{P}(\mathrm{x})_{\mathrm{w}^{\prime \prime}}$

Pressuposição:

$\forall \mathrm{w}^{\prime} \in \mathrm{F}_{\mathrm{w}}^{\prime} \forall(\mathrm{x})\left(\mathrm{P}(\mathrm{x})_{\mathrm{w}} \rightarrow \exists \mathrm{w}^{\prime}\left(\mathrm{D}(\mathrm{x})_{\mathrm{w}}\right)\right)$

$\mathrm{P}=$ problemas-passíveis-no-computador

$\mathrm{D}=\mathrm{dar}$

Note que consideramos todas as alternativas na base modal e, além disso, garantimos que na base modal há pelo menos dois mundos que contêm alternativas distintas. O resultado é que em cada mundo que compõe o conhecimento do falante o computador tem um problema diferente e todas as hipóteses são possíveis, logo, por inferência, o falante não sabe qual é o problema do computador no mundo atual.

Essa análise se aplica diretamente a casos em que o qualquer tem interpretação "existencial" na posição de objeto, como na sentença em (48):

$$
\text { A Maria escutou qualquer barulho (lá fora). }
$$


Há um conjunto de barulhos possíveis de serem escutados, que é restrito contextualmente (se a Maria estiver numa chácara isolada é um conjunto, se num apartamento na avenida São João é outro,...), e a base modal é epistêmica, dado que inferimos que a Maria não sabe exatamente qual barulho ela escutou. Segundo nossa proposta, para cada barulho possível há um mundo em que a Maria escutou esse barulho.

Vamos agora considerar o exemplo (40), repetido aqui por conveniência:

(49) A Maria coloca qualquer roupa quando está em casa.

Trata-se de uma sentença genérica habitual, e o sintagma qualquer está sob o escopo de um existencial. A base modal parece ser contrafactual porque o que se veicula é que não importa o referente escolhido desde que ele pertença ao conjunto de roupas-de-Maria-ficar-em-casa. Precisamos garantir, mais uma vez, que não haja uma alternativa que possa ser a escolhida em todos os mundos da base modal, porque nesse caso não seria verdadeiro que o referente não importa, já que há um que pode ser o referente em todos os mundos. Uma das inferências disparadas por (49) é que Maria não escolhe qual roupa, do conjunto de roupas para ficar em casa, ela veste quando está em casa. Ela não tem, portanto, preferência por nenhuma das alternativas possíveis. Se, por acaso, um referente fosse o escolhido em todos os mundos, então a Maria teria preferência por ele.

(50) Restrição à base modal:

$\mathrm{F}^{\prime}=\mathrm{F}($ base modal $) \cap \exists \mathrm{w}^{\prime}, \mathrm{w}^{\prime \prime}: \mathrm{R}(\mathrm{x})_{\mathrm{w}^{\prime}} \neq \mathrm{R}(\mathrm{x})_{\mathrm{w}^{\prime \prime}}$

Pressuposição:

$\forall \mathrm{w}^{\prime} \in \mathrm{F}_{\mathrm{w}}^{\prime} \forall(\mathrm{x})\left(\mathrm{R}(\mathrm{x})_{\mathrm{w}} \rightarrow \exists \mathrm{w}^{\prime}\left(\mathrm{V}(\mathrm{x})_{\mathrm{w}}\right)\right)$

$\mathrm{R}=$ roupa-de-Maria-ficar-em-casa

$\mathrm{V}=$ vestir

Em linguagem informal, para todos os mundos próximos ao nosso, e para todos os elementos do conjunto de roupas para ficar em casa, há um mundo em que a Maria usa um desses elementos. O resultado é que temos vários mundos e a Maria usa, em cada um deles (em pelo menos dois deles), roupas distintas de ficar em casa. Já que todas as alternativas são igualmente possíveis, infere-se daí que Maria não escolhe qual roupa de ficar em casa ela usa. 
Vejamos, agora, a análise de uma sentença que expressa indiferença, como no exemplo em (41). Esta sentença afirma que, em geral, adolescentes choram, como aparece em (41a). A semântica do operador genérico, GEN, é em si mesma tópico de discussão e, como dissemos, não interessa discutir, neste artigo, essa questão. Sem justificar, vamos assumir que este operador pode ser parafraseado informalmente por em geral. ${ }^{13}$ Assim, a sentença asserta que em geral adolescente chora. Para todos os pares de adolescente e mundo é verdade que se algo é adolescente em um mundo, então ele chora em todos os mundos relevantes (aqueles em que ele se encontra numa situação de choro; afinal, ele não chora sempre). Até aqui estamos destrinchando, muito informalmente, a asserção. Resta, ainda, entendermos o que faz a pressuposição disparada por qualquer.

Segundo a hipótese que desenvolvemos, ao usar qualquer o falante ao mesmo tempo supõe uma base modal e um conjunto de elementos. $\mathrm{Na}$ sentença em questão parece claro que o falante está expressando indiferença, não importa qual adolescente é escolhido, será verdadeiro que ele chora. Seguindo von Fintel (2002), podemos captar indiferença adotando uma base modal contrafactual. Fala-se, portanto, sobre todos os mundos que são semelhantes ao mundo atual do falante, incluindo o mundo atual do falante. Neste caso, o conjunto de adolescentes contextualmente relevante constitui-se de todos os adolescentes do mundo atual e de todos os mundos que são próximos ao nosso. ${ }^{14}$

Como é o caso da intepreteção epistêmica, é preciso que haja alternativas de conjuntos de adolescentes para que o uso de qualquer seja feliz. Garante-se assim que o falante não sabe qual é o conjunto de adolescente que ele está considerando, daí a inferência de que a escolha é aleatória, cega. Este é, na verdade, o traço distintivo de qualquer: a existência de alternativas possíveis. Sem essas alternativas, a generalização em (41a) é verdadeira, mas a generalização em (41) não. Reside aqui, aparentemente-

\footnotetext{
13 Veja Krifka et al. (1995) para diferentes propostas. A versão modal é: GEN $\left[\mathrm{x}_{\mathrm{i}} \ldots \mathrm{x}_{\mathrm{i}} ; \mathrm{y}_{\mathrm{i}} \ldots \mathrm{y}_{\mathrm{i}}\right]$ (Restritor; Matrix) é verdadeiro em w relativo a uma base modal $\mathrm{B}_{\mathrm{w}}$ e a uma fonte de ordenação $\leq_{\mathrm{w}}$ sse:

Para todo $\mathrm{x}_{\mathrm{i}}, \ldots \mathrm{x}_{\mathrm{j}}$ e todo $\mathrm{w}^{\prime} \in \mathrm{B}_{\mathrm{w}}$ tal que Restritor $\left[\mathrm{x}_{\mathrm{i}} \ldots \mathrm{x}_{\mathrm{j}}\right]$ é verdadeiro em w', tem um mundo w" em $\mathrm{B}_{\mathrm{w}}$ tal que w" $\leq_{\mathrm{w}} \mathrm{w}^{\prime}$, e para todo mundo $\mathrm{w}^{\prime \prime} \leq_{\mathrm{w}} \mathrm{w}^{\prime}, \exists \mathrm{y}_{\mathrm{i}} \ldots \mathrm{y}_{\mathrm{j}}$ Matrix $\left[\left\{\mathrm{x}_{\mathrm{i}}\right\} \ldots\left\{\mathrm{x}_{\mathrm{j}}\right\}, \mathrm{y}_{\mathrm{i}} \ldots \mathrm{y}_{\mathrm{j}}\right\}$ é verdade em w”'. (1995: 52, tradução minha).

14 Como na proposta de Kratzer (1981) estamos adotando implicitamente uma fonte de ordenação, embora ela não apareça nas fórmulas.
} 
mente, mas este é um tópico que também precisa ser melhor investigado, a diferença entre uma sentença com qualquer e uma sentença com um singular nu, como Adolescente chora: a existência de alternativas é necessária para o qualquer, e apenas possível para o singular nu.

Mantem-se, portanto, a restrição à base modal. Significa que teremos, nos diferentes mundos da base modal, pelo menos dois conjuntos diferentes de adolescentes. Eis a caracterização formal da pressuposição:

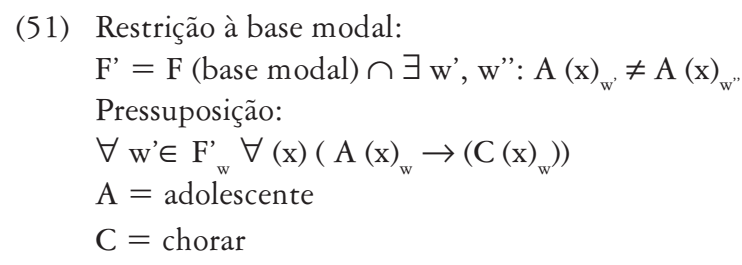

Em termos informais: para todo adolescente que pertence ao conjunto relevante de adolescentes é verdade que este adolescente chora. Note que ao compormos a pressuposição com a asserção o único fator distintivo é o fato de que na sentença com qualquer há que se considerar alternativas diferentes de adolescentes, o que permite a inferência de que não importa qual elemento seja considerado. É nesse sentido que a generalização com qualquer é mais ampla: ela não se aplica a situações em que há mesmo indivíduo é escolhido como valor em todas as alternativas de mundo, mesmo quando ele é usado com um partitivo, em que o conjunto de indivíduos é fixo em todos os mundos. Vejamos esse caso.

(52) Qualquer um dos dois (adolescentes) chora.

Para que a sentença em (52) seja verdadeira é preciso que a generalização se aplique aos dois indivíduos e, portanto, que não faça diferença qual é o escolhido. A situação que precisa ser eliminada é uma em que o mesmo indivíduo é escolhido em todos os mundos da base, precisamente o que a restrição impede.

Consideremos, agora, um caso em que qualquer ocorre na posição de objeto de uma sentença genérica. Suponha a sentença, como resposta a uma indagação sobre restrições alimentares:

(53) Eu como qualquer coisa. 
Segundo a hipótese que estamos formulando, qualquer dispara a pressuposição de que para toda coisa que é comestível, é o caso que o falante come. Ele não expressa preferência por nenhuma dessas coisas: se o x for camarão, ele come; se o x for feijoada, ele come; se o x for churrasco, ele come; se o x for uma saladinha macrobiótica, ele come.

A hipótese da pressuposição que estamos apresentando explica também os casos em que qualquer aparece em contextos de verbos de atitude proposicional ou modais. Considere o exemplo abaixo, que está na literatura desde que ele foi discutido (1967):

(54) Pegue qualquer maçã.

Trata-se de uma sentença no modo imperativo. O ponto que nos interessa é que ela só pode ser usada com felicidade, se houver um conjunto de maçãs contextualmente saliente. E este conjunto deve conter no mínimo duas maçãs, em contraste com a sentença com o indefinido um em que esta restrição não se coloca. Além disso, a sentença em (54) parece expressar desconhecimento do falante, afinal o falante não sabe qual alternativa será escolhida pelo ouvinte. Estamos, portanto, diante de uma base modal epistêmica. Nessa base, todas as alternativas estão disponíveis; em outros termos, para cada maçã há um mundo em que o ouvinte escolhe aquela maçã. A hipótese da pressuposição se aplica satisfatoriamente.

\subsection{Partitivos}

Há ainda uma questão que merece ser discutida: o fato de que sintagmas-qualquer podem ser usados com partitivos, como em qualquer escritor desse grupo, um escritor qualquer desse grupo. Este aspecto pode ser problemático porque na hipótese sobre a pressuposição estipulamos que deve haver alternativas possíveis. Da maneira como fizemos, o que ocorre é que o falante não sabe qual conjunto está sendo considerado em qual mundo. Mas se temos um uso partitivo, então o falante sabe precisamente qual é o conjunto. Se, por exemplo, retomamos a situação das dez bicicletas e o falante sabe que apenas duas delas são alternativas possíveis para a Maria, ele pode, com felicidade, proferir a sentença:

(55) A Maria comprou qualquer uma dessas duas bicicletas. 


\section{Qualquer conclusão é provisória}

Do ponto de vista teórico, este artigo, se estiver no caminho certo, pode dar duas contribuições: em primeiro lugar, a despeito do que a literatura sobre livre-escolha, na sua maioria, tem tomado como certo, livreescolha é independente da força quantificacional. Se isso é assim, então é preciso rever a descrição de any. Essa dissociação permite ainda entender porque alguns usos de some indicam livre-escolha. Em segundo lugar, a hipótese da pressuposição de alternativas, embora com base em von Fintel (2000) é original e deveria, em princípio, funcionar para outros itens de livre-escolha tanto do PB quanto de outras línguas.

Este artigo também contribui para compreendermos melhor os sintagmas nominais no PB, em especial aqueles que têm sido considerados como quantificados. Se a hipótese que levantamos está correta, então ela pode explicar em várias camadas as diferenças entre as sentenças:

(56) Toda criança tem direito à escola.

(57) Qualquer criança tem direito à escola.

Em primeiro lugar, só em (56) temos um sintagma quantificado; em segundo, apenas a sentença em (57) precisa, para ser feliz, que haja um conjunto de crianças já disponível no contexto, ao passo que todo não sofre essa restrição de uso. Somente uma pesquisa empírica poderia confirmar essa última hipótese. Mas há talvez alguns dados que falam a seu favor. Por que dizemos toda e qualquer e não qualquer e toda? A hipótese que aventamos explica este fato: toda introduz o conjunto de alternativas que é pressuposto por qualquer.

(58) Toda e qualquer criança tem direito à escola.

Também podemos explicar a diferença entre as sentenças abaixo ${ }^{15}$ :

(59) Todo camarão que você quiser por $\mathrm{R} \$ 5,00$

(60) Qualquer camarão que você quiser por $\mathrm{R} \$ 5,00$

Ao menos em algumas situações, as sentenças acima não expressam o mesmo. E se elas fossem placas na frente de dois restaurantes distintos na

15 O exemplo aparece em Gomes (2004). 
lagoa da Conceição, um paulista voraz por camarão provavelmente escolheria o restaurante com a placa em (59). A interpretação da sentença em (60) é paralela à sentença em (54), o falante ignora qual camarão será o escolhido, mas trata-se de uma escolha.

Sem qualquer dúvida, há ainda muito a ser estudado. No mínimo faltou dizer algo sobre a relação do qualquer com a negação, mas "este papo já tá qualquer coisa" (Qualquer coisa, Caetano Veloso).

E-mail: pires@cce.ufsc.br Recebido em fevereiro de 2005 Aprovado em março de 2005

\section{REFERÊNCIAS}

ChierchiA, G. 1995. Dynamics of meaning: anaphora, presupposition, and the theory of grammar. Chicago: Chicago University Press.

DAYAL, V. 1997. Free Relatives and Ever: Identity and Free Choice Reading. Semantics and Linguistics Theory 7.

. 1998. Any as inherently modal. Linguistics and Philosophy 21(5): 433-476.

von Fintel, K. 2000. Whatever. Proceedings of the Salt Conference.

Giannakidou, A. 2001. The meaning of Free Choice. Linguistics and Philosophy 24: 659-737.

Gomes, A.P. 2004. 'Todo', 'cada' e 'qualquer': exigências sobre a denotação nominal e a verbal. Dissertação de Mestrado, não publicada. USP.

Guimarães, M. R. 1995. Sobre a Semântica de Qualquer. Revista LETRAS. Curitiba. Vol. 44: 54-66.

Haspelmath, 1997. Indefinite Pronouns. Oxford: Claredon.

HeIm, I. 1982. The Semantics of Definite and Indefinite Noun Phrases. UMass Dissertation.

1990. On the projection problem for presupposition. In: S. Davis (ed.) Pragmatics. Oxford: Oxford University Press: 397-405.

Horn, L.R. 1989. A Natural History of Negation. Chicago: Chicago University Press.

2002. Any and (-ever): Free Choice and Free Relatives. Ms. Yale University. On line.

Kadmon, N. and F. Landaman. 1993. Any. Linguistics and Philosopby 16: 353-422. 
Kartunen, L. 1974. Presuppositions and Linguistic Context. Theoretical Linguistics 1: 181-194.

Kratzer, A. 1981. The Notional Category of Modality. In: H.-J. Eikmeyer \& H. RiESER (eds.). Words, worlds and contexts: new approaches to word semantics. Berlin: de Gruyter: 38-74.

Kratzer, A. and Shimoyama. 2002. Indeterminate Pronouns: The view from Japanese. Paper presented at the $3^{\text {rd }}$ Tokio Conference in Psycholinguistics.

KrIFKA, et al. 1995. Genericity: an Introduction. In Carlson, G.N. \& F.J. Pelletier (eds.) The Generic Book. Chicago \& London: The University of Chicago Press: 1-124.

Y.-S. Lee \& L. Horn. 1995. Any as indefinite plus even. Ms: Yale University.

Mattewson, L. 2001. Quantification and the nature of cross-linguistic variation. Natural Language Semantics 2: 145-189.

MóiA, T. 2002. Aspectos da Semântica do operador qualquer. On line.

Müller, A.2002. The Semantics of Generic Quantification in Brazilian Portuguese. PROBUS. 14 (2): 145-289.

Negrão, E.V. 2002. Distributividade e genericidade nos sintagmas introduzidos por cada e todo. Revista do GEL. N. Especial: 185-205.

Peres, J. 1987. Para uma semântica formal da quantificação nominal não-massiva. Dissertação de Doutorado, Universidade de Lisboa. . 1992. Questões de Semântica Nominal. Cadernos de Semântica 1. Faculdade de Letras da Universidade de Lisboa.

Pesetsky, D. 1987. WH-in situ: movement and unselective binding. In: E. Reuland \& A.G.B. terMeulen (eds.) The Linguistic Representation of (In)definiteness. Cambridge: MIT Press: 98-129.

Pires de Oliveira, R. 2003. Is todo N in Brazilian Portuguese a quantifier? In: Anderssen, J., P. Menéndez-Benito, A. Werle (eds.) The Proceedings of SULA 2. Vancouver BC. 99-116. GLSA. University of Massachussets, Amherst.

Stalnaker, R. 1974. Pragmatic Presuppositions. In Munitz, M. and P. Unger (eds.) Semantics and Philosophy. New York University Press.

Vendler, 1967. Linguistics in Philosophy. Ithaca: Cornell University Press. 